\title{
The Use of an Improved Technique in the Rabbit Gastrointestinal Tract Mummification
}

\author{
Ioana DUMITRU*, Cristian DEZDROBITU, Bianca MATOSZ, Cristian MARTONOS, Florin SILAGHI, \\ Aurel DAMIAN \\ ${ }^{1}$ University of Agricultural Science and Veterinary Medicine Cluj-Napoca, str. Calea Mănăştur 3-5 Cluj- \\ Napoca, Romania. \\ *Corresponding author: ioanadumitru19@yahoo.ro
}

Bulletin UASVM Veterinary Medicine 73(1) / 2016,

Print ISSN 1843-5270; Electronic ISSN 1843-5378

DOI:10.15835/buasvmcn-vm: 10351

\begin{abstract}
The mummification of bodies is a technique known since antiquity. Over time it has spread to Europe, becoming an essential practice for preserving bodies. The mummification technique was associated with the existence of life after death. The discipline of Comparative Anatomy in veterinary medical education uses animal bodies as educational models for teaching purposes. The study was conducted in the laboratory of Anatomy of the University of Agricultural Sciences and Veterinary Medicine of Cluj-Napoca. We used: rabbit cadavers, dissection instruments, staining substances and 5\% formalin solution. The staining substance was injected through aorta, then; fixation in $5 \%$ formaldehyde solution for five days was performed. The gastrointestinal mass was isolated and the content was evacuated and then, fixed to the support and left to dry until mummification occurred. The gastrointestinal mass was properly preserved and the dye has uniformly highlighted the vascularization of all segments. The fixing method allowed the maintenance of injected stains.

The results indicate that the technique applied in this study is appropriate for preservation of the gastrointestinal tract in rabbits.
\end{abstract}

Keywords: Gastrointestinal tract, mummification, rabbit

\section{INTRODUCTION}

The mummification technique was associated with the existence of life after death (Johnson et al., 2012). The discipline of Comparative Anatomy in veterinary medical education uses animal bodies as educational models for teaching purposes.

The history of embalming or preserving human bodies goes back to 4000 B.C. (McDonald, 1989). Embalming practice started as a simple treatment of the body with herbs and developed into a complex procedure using chemical solutions. In the nineteenth century, techniques were developed for infusion of embalming fluid into the vascular system. Formaldehyde has been used as a preserving and embalming agent, since its tissue-hardening properties were discovered in 1893 (Bjorkman et al., 1986). During the course of their work, embalmers were exposed to formaldehyde and its polymers. Exposure to formaldehyde has three types of health effects like irritation, immunologically mediated sensitivity and carcinogenicity (Moore and Ogrodnik, 1986; Hathaway et al., 1991; OSHA, 1994). The acute and chronic respiratory function effects of formaldehyde are unclear at this time. Liquid formaldehyde may irritate the skin, causing a rash or burning feeling on contact. It can also cause severe burns, leading to permanent damage. Because of its chemical reactivity and high water solubility, formaldehyde exposure irritates the nose, mouth and throat.

Exposure to high concentrations of formaldehyde in air can cause a build-up of fluid in the lungs or spasms of the windpipe, and edema of 
the larynx. It has been shown to cause cancer of the nasal passages in animals. Allergic reactions and superficial coagulative necrosis have been associated with formaldehyde exposures (ACGIH, 1992).

\section{AIMS AND OBJECTIVES}

The research aim of present paper is to improve the classical (standard) method of mummification by means of staining substances and to observe the technique efficiency in case of the rabbit viscera.

\section{MATERIALS AND METHODS}

The study was conducted in the laboratory of Anatomy of the University of Agricultural Sciences and Veterinary Medicine of Cluj-Napoca. Materials used were: three rabbit cadavers, dissection instruments, catheters, syringes, needles, acrylic staining and $5 \%$ formalin solution. After dissection, staining substance was injected through the aorta, and then the fixation in 5\% formaldehyde solution for five days was performed. The gastrointestinal mass was isolated and the content was evacuated and then fixed to the support and left to dry until mummification occurred.

\section{RESULTS AND DISCUSSION}

The present study has applied the mummification technique, focusing on preservation level of the anatomical characteristics and reducing the work time and costs. The gastrointestinal mass was properly preserved and the dye has uniformly highlighted vascularization of all segments. The fixing method allowed the maintenance of the injected stain.

\section{CONCLUSION}

Corroborating the results of the mummification technique applied in this study, we have formulated the following conclusions:

The technique applied is appropriate for preservation of the gastrointestinal tract in rabbits.

The obtained material can be used for students during teaching.

The staining agent underlined the vascularization on all segments of the gastro-intestinal tract.

Acknowledgements. This paper was published under the frame of European Social Fund, Human Resources Development Operational Programe 2007-2013, project no. POSDRU/159/15/S/ 132765 .

\section{REFERENCES}

1. American Conference of Governmental Industrial Hygienist (ACGIH) (1992). Notice of Intended ChangeFormaldehyde. Appl Occup Environ Hyg 7(12):852-874.

2. Bjorkman N, Nielsen P, Meller VH (1986). Removing Formaldehyde from Embalmed Cadavers by Percolating the Body Cavities with Dilute Ethanol. ACTA Anat 126:7883

3. Hathaway GJ, Proctor NH, Hughes JP, Fischman ML (1991). Proctor and Hughes' Chemical Hazards of the Workplace. Third ed, Van Nostrand Reinhold Press, New York, 305308.

4. Johnson EC, Johnson GR, Johnson M (2012). The origin and history of embalming. In : Mayer RG (ed). EmbalmingHistory, Theory and Practice, McGraw-Hill, New York, 467-509.

5. McDonald L (1989). Blood Exposure and Protection in Funeral Homes. Am J of Infect Control 17(4):193-195.

6. Moore LL, Ogrodnik EC (1986). Occupational Exposure to Formaldehyde in Mortuaries. J Environ Health 49(1):3235.

7. Occupational Safety and Health Administration (OSHA) (1994). Occupational Safety and Health Standards Subpart Z -Toxic and Hazardous Substances Hazard Communication Standard, Code of Federal Regulation, Title 29, Chapter XVII, Part 1910, Subpart Z, Section 1910.1200 